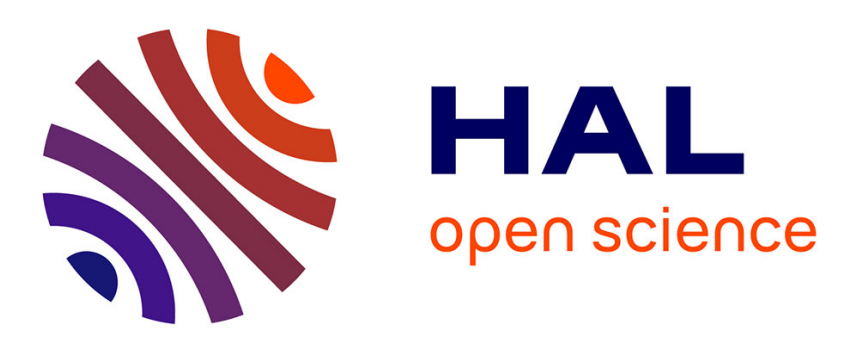

\title{
Combining Nanoparticles grown by ALD and MOFs for gas separation and catalysis applications
}

\author{
Matthieu Weber, Mikhael Bechelany
}

\section{To cite this version:}

Matthieu Weber, Mikhael Bechelany. Combining Nanoparticles grown by ALD and MOFs for gas separation and catalysis applications. Pure and Applied Chemistry, 2020, 92 (2), pp.213-222. 10.1515/pac-2019-0109 . hal-03242932

\section{HAL Id: hal-03242932 \\ https://hal.umontpellier.fr/hal-03242932}

Submitted on 31 May 2021

HAL is a multi-disciplinary open access archive for the deposit and dissemination of scientific research documents, whether they are published or not. The documents may come from teaching and research institutions in France or abroad, or from public or private research centers.
L'archive ouverte pluridisciplinaire HAL, est destinée au dépôt et à la diffusion de documents scientifiques de niveau recherche, publiés ou non, émanant des établissements d'enseignement et de recherche français ou étrangers, des laboratoires publics ou privés. 


\author{
Institut Européen des membranes, IEM, UMR-5635, Université de Montpellier, \\ ENSCM, CNRS, Place Eugène Bataillon, 34095 Montpellier cedex 5, France
}

\title{
Combining Nanoparticles grown by ALD and MOFs for gas separation and catalysis applications
}

\begin{abstract}
Supported metallic nanoparticles (NPs) are essential for many important chemical processes. In order to implement precisely tuned NPs in miniaturised devices by compatible processes, novel nanoengineering routes must be explored. Atomic layer deposition (ALD), a scalable vapor phase technology typically used for the deposition of thin films, represents a promising new route for the synthesis of supported metallic NPs. Metal-organic frameworks (MOFs) are a new exciting class of crystalline porous materials that have attracted much attention in the recent years. Since the size of their pores can be precisely adjusted, these nanomaterials permit highly selective separation and catalytic processes. The combination of NPs and MOF is an emerging area opening numbers of applications, which still faces considerable challenges, and new routes need to be explored for the synthesis of these NPs/MOF nanocomposites. The aim of this paper is double: First, it aims to briefly present the ALD route and its use for the synthesis of metallic NPs. Second, the combination of ALD-grown NPs and MOFs has been explored for the synthesis of Pd NPs/MOF ZIF-8, and several selected examples were ALD-grown NPs and MOFs have been combined and applied gas separation and catalysis will be presented.
\end{abstract}

Keywords: Atomic layer Deposition, Metal-Organic Frameworks, gas separation, sensing, catalysis

\section{Introduction}

Metallic nanoparticles (NPs) have gained a lot of interest in research because they can be applied in many different fields, such as biomedicine, ${ }^{1}$ magnetic recording, ${ }^{2}$ plasmonics, ${ }^{3}$ water purification ${ }^{4}$ and, most importantly, heterogeneous catalysis. ${ }^{5,6}$ Heterogeneous catalysis is by far the main application of metallic NPs. Supported metallic NPs are employed as nanocatalysts in many important technologies, for example in oil refining, automobile emission control, or fuel cells. ${ }^{6,7}$

Although various methods exist to synthesize metallic NPs, based either on wet chemistry or vapor phase deposition, ${ }^{5,8-13}$ there is much interest in finding new methods to synthesize improved nanocatalysts. The most commonly used techniques are solution-phase colloidal chemistry routes, which are very versatile techniques to synthesize metallic NPs. Briefly, the preparation of metallic NPs using these routes involve the reduction or the thermal decomposition of the metal precursors in the presence of a stabilizer and/or surfactant. The size and shape of the NPs can then be controlled by varying the process parameters. ${ }^{7,12-15}$ Gas phase routes, either physical vapor deposition (PVD) or chemical vapour deposition (CVD) techniques, have also been applied to the synthesis of supported metallic NPs. ${ }^{16}$ The main advantage of gas phase methods is the opportunity to produce a large amount of NPs directly supported on a chosen surface, and the process potential upscaling is thus easier than with the colloidal techniques. The control of the NPs dimensions is however more challenging. ${ }^{5,8-13}$

The search for a novel route to prepare NPs that can be tuned at the nanoscale is extremely important because their industrial applications are huge, and because many noble metals are scarce. In addition, there is a need to implement precisely engineered NPs in miniaturised devices such as micro fuel cells for example. Thus, new nanoengineering routes must be explored for the preparation of metallic NPs.

A promising new route for the synthesis of supported NPs is atomic layer deposition (ALD). Atomic layer deposition (ALD), a CVD derived route, is a vapor phase technology typically used for the deposition of thin films of high quality materials, offers many opportunities for nanoengineering also in the field of NPs. 
The combination of nanomaterials prepared by ALD and other techniques open various prospects for a wide range of applications. For example, the ALD and electrodeposition routes have been combined to produce $\mathrm{Cu}_{2} \mathrm{O} \backslash \mathrm{ZnO}$ nanostructures and study their photoconductivity properties, ${ }^{17}$ and the formation of $\mathrm{Au} / \mathrm{ZnO}$ nanostructures has been achieved using ALD and PVD (magnetron sputtering), in order to study the contribution of plasmon resonance effects to the optical dispersion of gold nanostructures. ${ }^{18}$

MOFs are an emerging class of porous materials based on metal-containing nodes (secondary building units) and organic linkers. Microporous MOF materials have gained a lot of attraction in the recent years, due to their uniform channels, large internal surface areas, (sub)nanometer-sized cavities, thermal stability, and their tunability. ${ }^{19-22} \mathrm{MOFs}$ materials with defined porosity are promising candidates for a myriad of applications, such as chemical catalysis, sensing, and most importantly, gas storage and separation. ${ }^{23,24}$ Due to their exceptional structural and functional tunability, the field of MOFs has become one of the most expanding area in chemistry. ${ }^{21}$

The combination of metallic NPs and MOFs attracts much attention because of the benefits of new chemical and physical properties, which could be extremely beneficial for catalysis and gas separation purposes. NPs/MOF nanocomposites can be prepared either by encapsulating presynthesized NPs by surrounding them with MOFs, ${ }^{25-27}$ or by using MOFs as templates to generate NPs within their pores. ${ }^{28-31}$ Although there are several reports on NPs/MOF composites and their applications, this emerging area still faces significant challenges, one of the main one being the control over the precise nanostructure of the NPs. ${ }^{32,33}$ Thus, new nanomanufacturing routes need to be explored for the synthesis of these NPs/MOF nanocomposites. ${ }^{32,34,35}$

In this paper, the ALD route and its use for the synthesis of precisely controlled metallic NPs are first presented. Then, the combination of ALD-grown NPs and MOFs has been explored for the synthesis of Pd NPs/MOF ZIF-8, and several examples where these ALD NPs NPs/MOF nanocomposites materials have been applied to gas separation and catalysis will be described.

\section{Atomic Layer Deposition of metallic nanoparticles (NPs):}

ALD is a vapor phase deposition technique enabling the preparation of ultrathin films of inorganic materials such as oxides, ${ }^{36-39}$ nitrides ${ }^{40-44}$ and metals, ${ }^{45,46}$ with a subnanometer thickness control. ${ }^{47,48}$ The route can be used to coat challenging 3D substrates with a conformal and uniform layer of high quality material, a capability unique amongst film deposition techniques. ${ }^{48,49}$ ALD research began in the former USSR in the $1950 \mathrm{~s},{ }^{50,51}$ and the technology has been patented in the 1970's. ${ }^{51}$ In the 1990s, the semiconductors industry became strongly interested in ALD ${ }^{51,52}$ as this thin film technology became an enabling technology for microelectronic devices fabrication. Since then, the microelectronics industry is the key-driver of the ALD field. ALD-grown materials have a wide range of applications, from microelectronics ${ }^{53,54}$ to biosensing, ${ }^{55,56}$ and from membranes ${ }^{57}$ to nanocatalysis. ${ }^{58,59}$ Although the route has gained the strongest attention in the recent years, it is important to note that there was already interest in using ALD for catalysis applications in the mid-1990s. ${ }^{60,61}$

ALD is based on the sequential use of self-limiting chemical reactions which take place in a cycle-wise fashion. A typical ALD cycle consists of successive pulses of a precursor and reactant gases in a vacuum reactor, separated by purge steps, thus forming two half-cycles. Figure 1 presents a schematic illustration of an ALD cycle. 


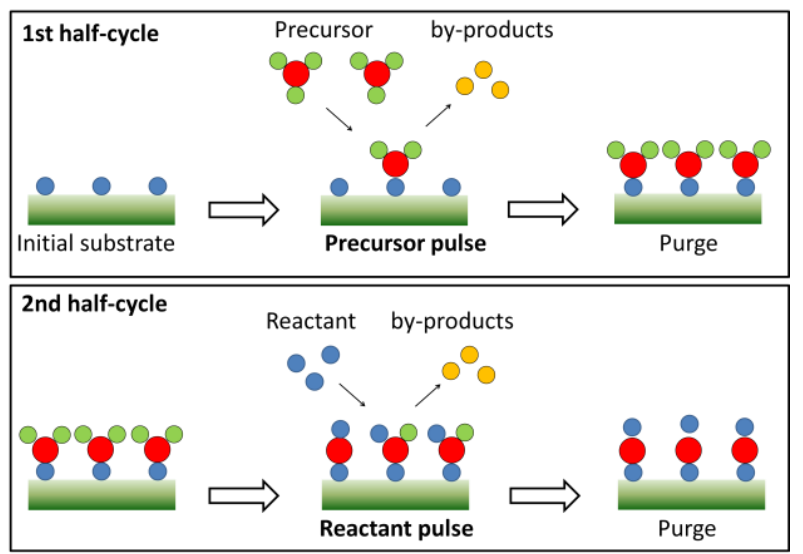

Fig. 1: Schematic representation of an ALD cycle. The substrate is exposed to a precursor and then purged in the first halfcycle. In the second half-cycle, the surface is exposed to a reactant and purged again.

A precursor is typically a metal center surrounded by chemical functional groups called ligands. The reactant chemistry is depending on the nature of the material to be deposited. Water or oxygen gas are typically used as reactant for the preparation of oxides, nitrogen containing reducing agents is used for nitrides or other reducing agents (e.g. $\mathrm{H}_{2}$ gas) can be applied for the synthesis of metals. Evidently, each precursor or reactant in an ALD process has a profound impact on the resulting film chemistry. ${ }^{47,62}$ The fact that ALD allows for an excellent conformality over the substrate is directly related to the self-saturated chemical surface reactions, as opposed to other flux controlled techniques such as sputtering for example.

With the increase of applications enabled by ALD, in areas such as membranes, ${ }^{57}$ catalysis, ${ }^{63}$ photovoltaics ${ }^{64}$ or sensing, ${ }^{55,65}$ new approaches for the integration of novel processes, substrates and precursor delivery techniques have been developed. These include energy-enhanced as well as spatial ALD processes involving plasma, direct-writing, atmospheric pressure, and roll-to-roll. ${ }^{66}$ For further and more detailed information about the ALD technology, the reader is referred to recent reviews in this area. ${ }^{48,53,66-70}$

As written above, many ALD surface chemistries can be applied, depending on the processes used and materials to be prepared. The process leading to the preparation of metallic materials is somewhat different than for the synthesis of binary compounds (e.g. oxides or nitrides). One difference is that in metal ALD, the deposition of a metallic material containing one single element has to be achieved. Thus, the reactant must permit the removal of the organic ligands (of the adsorbed metallic precursor), but without being incorporated in the synthesized film. The chemistries used can be based on hydrogen reduction, combustion chemistry, or fluorosilane elimination, among others. ${ }^{37,48}$

In most $\mathrm{ALD}$ processes, such as $\mathrm{ALD}$ of $\mathrm{Al}_{2} \mathrm{O}_{3}$ for example, the growth of a uniform film on a substrate starts already after a few cycles, and the nucleation of the film and subsequent continuous growth is straightforward. In the case of ALD of metals, the film has typically more difficulties to grow, and a nucleation delay is typically observed before the formation of a closed film. In fact, because of the difference in surface energies ${ }^{71}$ between the substrate and the metal to be deposited, ALD of metals usually starts with the formation of isolated clusters at the surface. This so-called Vollmer-Weber growth nucleation can be exploited to produce supported metallic NPs. These NPs grow with increasing number of cycles, coalesce and finally form a closed film on which the ALD growth continues at a constant rate. Figure 2 illustrates the nucleation of Platinum ALD, showing that Pt ALD starts from island growth, via island coalescence, to film closure. ${ }^{72}$ ALD is therefore a powerful tool for the direct synthesis of supported metallic NPs on challenging high aspect ratio substrates. 


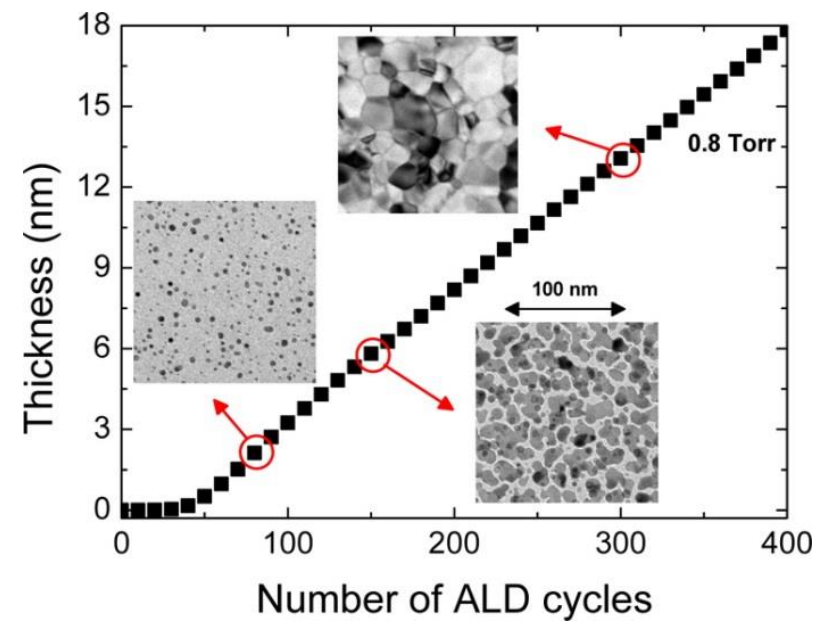

Fig. 2: Thickness as a function of the number of ALD cycles as measured by in situ spectroscopic ellipsometry (SE) $)^{73}$ for a Pt process based on $\mathrm{MeCpPtMe}_{3}$ precursor and $\mathrm{O}_{2}$ reactant. The bright field TEM images in the figure illustrate that Pt ALD nucleation evolves from island growth, via island coalescence, to film closure. Reprinted with permission from Reference ${ }^{72}$. Copyright 2013 American Chemical Society.

Strong research efforts have been carried out in order to gain an atomistic understanding of the evolution of the size distribution with temperature and number of cycles in (ALD) of metallic NPs. The growth mechanism includes the adsorption of precursor molecules at the substrate surface as well as the diffusion processes of metal adatoms to form clusters or to join growing NPs. The diffusion of atoms over the surface of the NP or within the NP themselves allows for a process of minimization to reduce the total surface free energy. Overall, the studies carried out have shown that NPs grow mostly via NP diffusion and coalescence, and that process parameters such as temperatures play a crucial role for their growth. ${ }^{63,68,72-75}$

ALD was therefore used in order to achieve the controlled synthesis of high purity metallic NPs. A variety of metallic NPs have been prepared by ALD, including transition metals such as copper, cobalt, iron and nickel, ${ }^{76}$ as well as noble metals such as $\mathrm{Pd}, \mathrm{Pt}, \mathrm{Ag}, \mathrm{Au}, \mathrm{Ir}$ and $\mathrm{Ru}^{37,45,77-79}$ Due to their potential application as nanocatalysts, the noble metals Pd and Pt have been the most studied NPs by ALD.

ALD of palladium NPs has been the subject of many studies, and the NPs have been deposited on different oxides, such as $\mathrm{Al}_{2} \mathrm{O}_{3},{ }^{46,80} \mathrm{TiO}_{2},{ }^{81,82} \mathrm{SiO}_{2},{ }^{83}, \mathrm{SnO}_{2},{ }^{84} \mathrm{ZrO}_{2},{ }^{77} \mathrm{NiO}^{85}$ as well as on nitrides ${ }^{86}$ and high aspect ratio carbon based supports. ${ }^{87,88}$ In addition, the catalytic activity of Pd NPs prepared by ALD have been assessed for different chemical reactions, such as methanol, ${ }^{80}$ ethanol, ${ }^{82}$ isopropanol, ${ }^{88}$ glucose ${ }^{89}$ and glycerol oxidation. ${ }^{90}$ The Pd NPs have been applied to other applications as well, such as sensing for example. ${ }^{65}$ Figure 3 shows a TEM image presenting a high aspect ratio $(\mathrm{ZnO})$ nanowire decorated with Pd NPs prepared by ALD, that was applied to hydrogen sensing. ${ }^{65}$

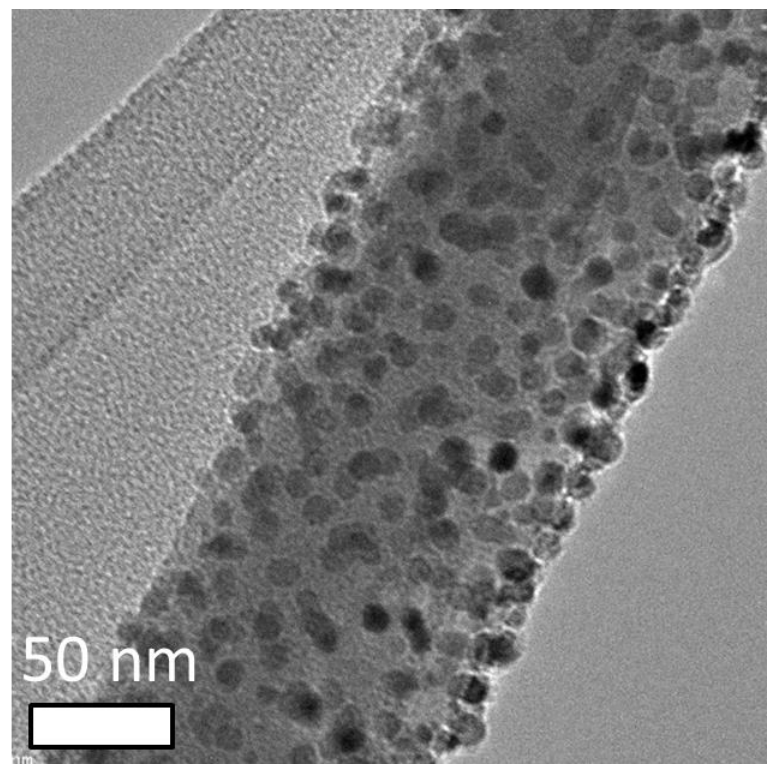

Fig. 3: TEM image of a single ZnO nanowire decorated with highly dispersed Pd NPs deposited by ALD. Reprinted with permission from Reference. ${ }^{65}$ Copyright 2018 American Chemical Society. 
The preparation of platinum NPs by ALD has focused strong attention as well, and the NPs have been exploited for catalytic purposes. For example, Liu et al. deposited Pt NPs on carbon nanotubes for proton-exchange membrane fuel cells, and they demonstrated that Pt nanocatalysts supported on CNTs have a higher utilization efficiency than commercial electrodes. ${ }^{91}$ Setthapun et al. prepared Pt NPs on various high surface area oxides supports, and demonstrated that these nanocatalysts had identical water gas shift reaction rates and kinetics to those reported in literature. ${ }^{92}$

The nanoengineering capabilities of ALD also enable the preparation of NPs with controllable nanostructures such as bimetallic NPs. In fact, both alloyed NPs and even core/shell NPs have been synthesized by ALD. Bimetallic Pt-Ru alloyed NPs were synthesized by alternating between Ru ALD and Pt ALD cycles. ${ }^{93}$ Using area-selective ALD processes,${ }^{94}$ core/shell NPs with different combinations of noble metals including Pd, Pt and Ru supported on oxides have been synthesized by the ALD route as well. ${ }^{95-97}$ In addition, independent and accurate control over the dimensions of both core and shell have been achieved. ${ }^{95}$ Such bimetallic NPs with controlled nanostructures prepared by ALD are presented in Figure 4.
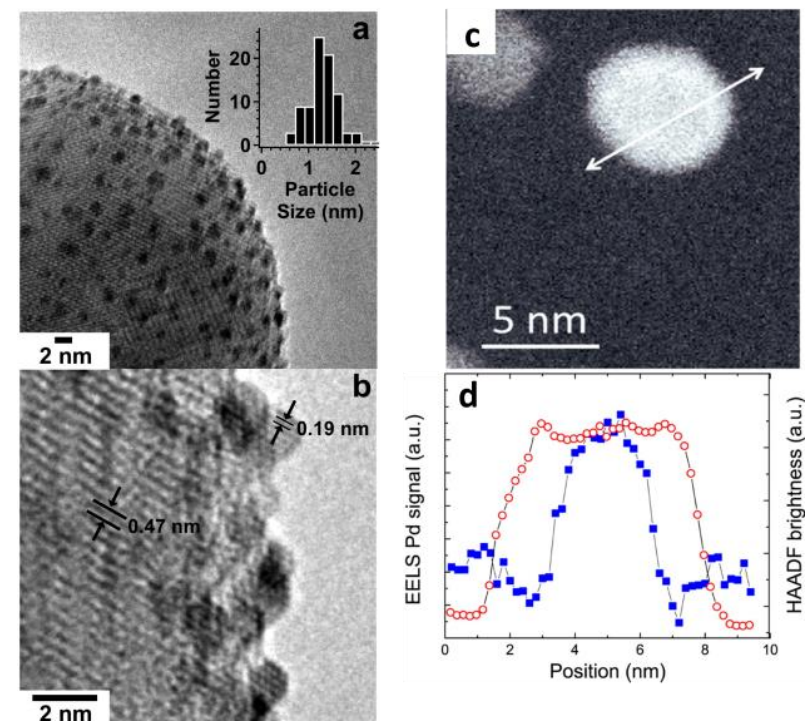

Fig. 4: Examples of bimetallic NPs with controlled nanostructures prepared by ALD: (a,b) TEM image of alloyed Ru-Pt NPs supported on an alumina sphere. Reprinted with permission from Reference ${ }^{93}$ Copyright 2010 American Chemical Society. (c) A single $\mathrm{Pd} / \mathrm{Pt}$ core/shell NP supported on alumina, and (d) EELS line scan across this $\mathrm{Pd} / \mathrm{Pt} \mathrm{NP}$. Reprinted with permission from Reference ${ }^{96}$ Copyright 2012 American Chemical Society.

\section{Combining ALD-grown NPs and MOFs:}

Both metallic NPs and MOFs present attractive but distinctive properties. Thus, combining these materials allows for a synergistic positive effect to take place, which is very attractive. In addition, the incorporation of metal clusters into MOFs can lead to significant improvements in porosity and stability of the MOFs materials. As described in the introduction, NPs/MOF nanocomposites are typically prepared either by encapsulating presynthesized NPs by surrounding them with MOFs or by using MOFs as templates to generate NPs within their pores. ${ }^{28-31}$

In our group, we recently took advantage of the combination of Pd NPs grown by ALD and MOFs (ZIF-8) materials for hydrogen separation and sensing. For this purpose, we synthesized palladium NPs by ALD on ZnO NWs, and partially converted such decorated NWs (using solvothermal conversion) in order to obtain a permselective ZIF-8 MOF top-layer, offering molecular sieving properties. ${ }^{98}$

The strategic combination of $\mathrm{ZnO}$ nanowires (NWs) decorated ALD-grown Pd NPs and a molecular sieve metal organic framework (MOF) nanomembrane (ZIF-8) were integrated within a miniaturized sensing device, and the results obtained showed that the performance of gas sensors towards $\mathrm{H}_{2}$ gas was greatly increased by using these ALD-grown NPs/composite nanomaterials. In fact; whereas the Pd NPs enabled the sensor to reach an intense signal response for $\mathrm{H}_{2}$ sensing, the MOF ZIF-8 overcoat enabled for an excellent selectivity. ${ }^{65}$ Figure 5 presents the results obtained with an integrated sensors based on bare $\mathrm{ZnO} \mathrm{NWs}, \mathrm{Pd} / \mathrm{ZnO} \mathrm{NWs}$ and ZIF-8 coated $\mathrm{Pd} / \mathrm{ZnO}$ NWs. It can be clearly seen that the permselective ZIF-8 layer allows for an efficient hydrogen separation from the other gases, which considerably enhance the selectivity of the sensor. 


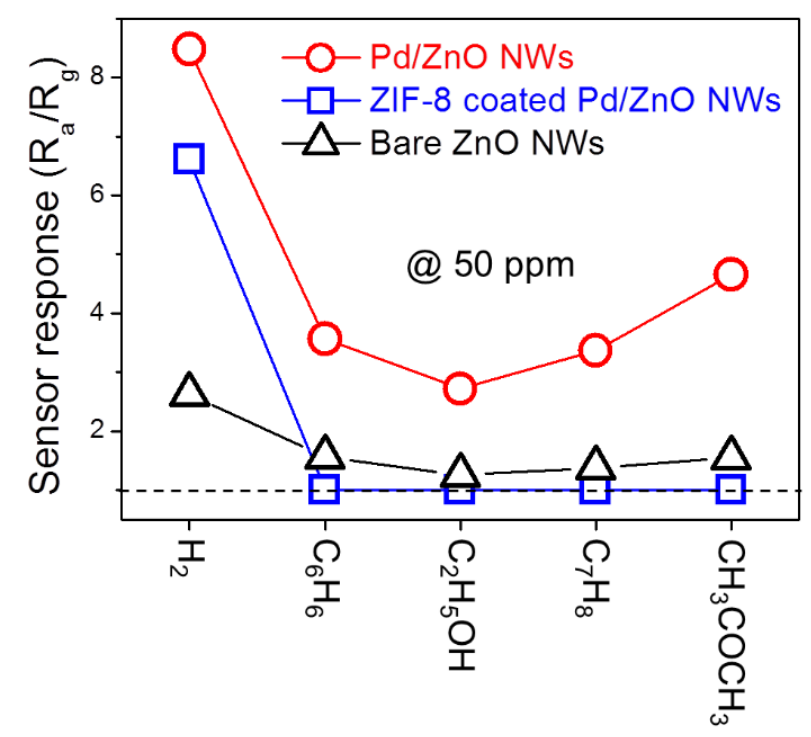

Fig. 5: Sensing responses of bare $\mathrm{ZnO} N W s, \mathrm{Pd} / \mathrm{ZnO} N W s$ and $\mathrm{ZIF}-8$ coated $\mathrm{Pd} / \mathrm{ZnO} \mathrm{NWs}$ gas sensors to $50 \mathrm{ppm}$ of $\mathrm{H}_{2}, \mathrm{C}_{6} \mathrm{H}_{6}$, $\mathrm{C}_{7} \mathrm{H}_{8}, \mathrm{C}_{2} \mathrm{H}_{5} \mathrm{OH}$ and $\mathrm{CH}_{3} \mathrm{COCH}_{3}$ gases in air at $200^{\circ} \mathrm{C}$. These results illustrate how the $\mathrm{ZIF}-8 \mathrm{MOF}$ allows for an enhanced selectivity. Reprinted with permission from Reference. ${ }^{65}$ Copyright 2018 American Chemical Society.

Considering the use of MOFs as templates to generate NPs within their porosity, the slow diffusion of ALD chemical precursors within the Ångstrom sized pores of MOFs makes ALD extremely challenging in these structures, but it can be achieved. Indeed, a few studies reported the insertion of metallic clusters NPs within such crystalline materials. The insertion of $\mathrm{Zn}, \mathrm{Co}, \mathrm{Cu}$, Ni in Zr-based NU-1000 MOF has been achieved by Klet et al., ${ }^{99}$ and the ALD of Pt clusters within MIL-101-Cr has been realized by the group of Detavernier. ${ }^{100,101}$

The penetration of precursor and replacement of metal nodes is extremely challenging. For example, considering a typical DEZ (diethylzinc) precursor within a Zr based mesoporous MOF, NU-1000, different ratios of incorporated metal ions $(\mathrm{Zn})$ to the $\mathrm{Zr} 6$ nodes have been observed depending on the ALD reactor temperature. Lower reactor temperatures prevented the dehydration of the Zr6 nodes and the loss of grafting sites (hydroxyl groups), resulting in better deposition of (four) $\mathrm{Zn}$ atoms per (Zr6) node. ${ }^{99}$

Pt ALD has been carried out in a MIL-101 MOF, which is based on pores with diameters in the low mesoporous regime $(\sim 25-35 \AA$ ). . ALD allowed for the synthesis of uniformly sized Pt NPs embedded within MIL-101 pores. Figure 6 presents the Pt Pt NPs/MIL-101 MOF nanomaterials obtained. In addition, the catalytic properties of nanocomposites were assessed for the hydrogenation of various olefins. ${ }^{100}$ 


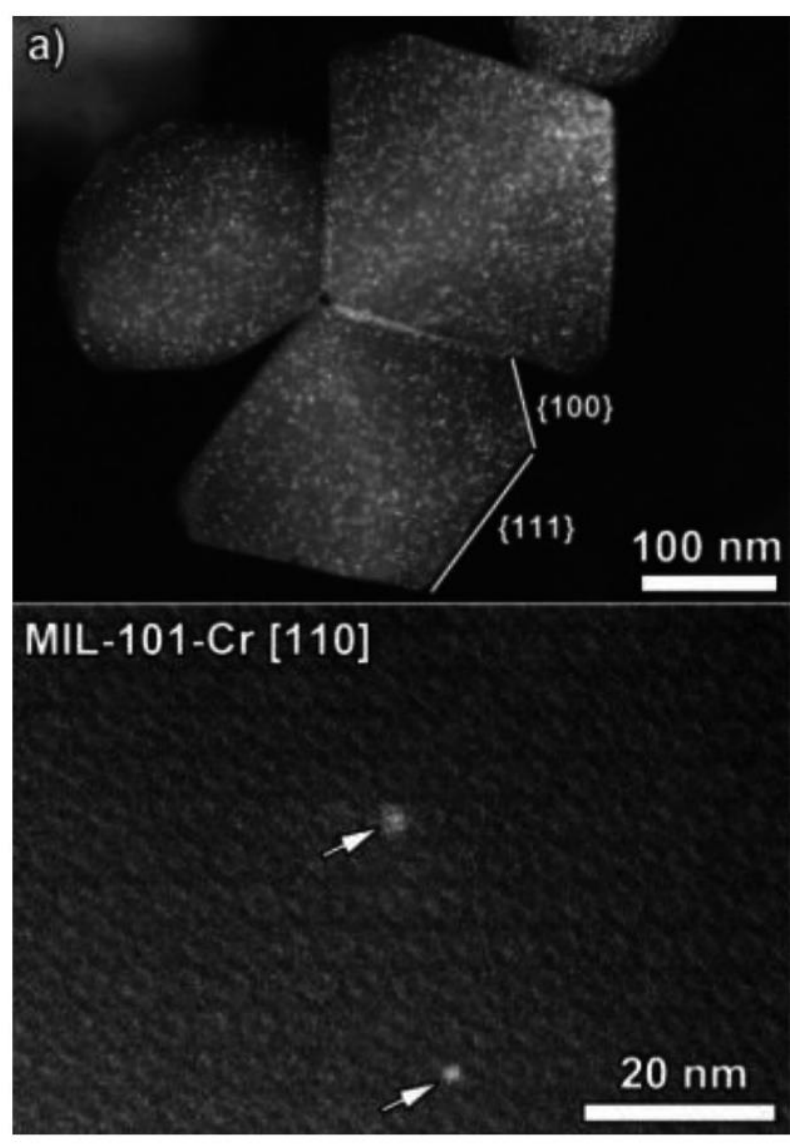

Fig. 6: Scanning transmission electron microscopy measurements (STEM) images of Pt@MIL-101-Cr using 120 cycles. The white arrows point to Pt nanoparticles with similar diameters to the MIL-101 framework pores. Taken and adapted from Reference. ${ }^{100}$ (Creative commons license).

The catalytic results obtained were promising, and the initial stability tests performed showed that the Pt NPs/MIL-101 MOF was stable for a long reaction time with very low Pt leaching and without loss of activity or crystallinity. Finally, it has to be noted that bimetallic NPs often present better properties than their monometallic counterparts. An exciting field of research would be the fabrication of bimetallic NPs/MOFs nanocomposites, which is a very challenging objective but could be achieved with this ALD strategy.

The composite materials fabricated by including ALD NPs to synergize with the intrinsic properties of MOFs allowed for enhanced properties when compared to the pure materials due to such synergistic effects. Thus, the strategy combining ALD processes and MOFs porous structures is a promising new route opening prospects for multifunctional devices such as gas detectors or catalytic reactors, for examples.

\section{Conclusions}

This paper presented ALD as a novel route for the synthesis of metallic NPs. The technique enables the preparation of supported NPs with controllable size, composition and nanostructure. Combining these ALD-grown NPs with MOFs allows for a synergistic positive effect to take place in these nanocomposites. We reported the synthesis of metallic NPs by ALD in combination with MOFs, and showed that these nanomaterials hold great promise for a myriad of purposes, especially in the fields of gas separation, sensing and catalysis. To illustrate this new strategy, we reported two examples where the synergistic combination of ALD-grown NPs and MOFs has been applied: Nanocomposites based on Pd NPs and ZIF-8 MOFs have been used for or hydrogen separation and sensing, and Pt NPs/MIL-101 MOFs have been successfully applied for the catalytic hydrogenation of various olefins.

In conclusion, we have demonstrated an effective strategy combining ALD processes and MOFs porous structures in order to provide access to new catalytically interesting functional materials. This strategy is applicable to a broad range of NPs and MOFs nanomaterials, and, considering the fact that the NPs can be precisely tuned by ALD and the number of existing MOFs structures, it is expected that this approach will be further exploited in the coming years. 


\section{Bibliography}

1 M. Mahmoudi, A. S. Milani and P. Stroeve, Int. J. Biomed. Nanosci. Nanotechnol., 2010, 1, 164-201.

2 T. Osaka, H. Iida, S. Tominaka and T. Hachisu, Isr. J. Chem., 2008, 48, 333-347.

3 J.-L. Wu, F.-C. Chen, Y.-S. Hsiao, F.-C. Chien, P. Chen, C.-H. Kuo, M. H. Huang and C.-S. Hsu, ACS Nano, 2011, 5, 959-967.

4 T. Pradeep, Thin Solid Films, 2009, 517, 6441-6478.

5 J. M. Thomas and W. J. Thomas, Principles and practice of heterogeneous catalysis, John Wiley \& Sons, 2014.

6 D. Astruc, F. Lu and J. R. Aranzaes, Angew. Chemie Int. Ed., 2005, 44, 7852-7872.

7 D. Astruc, Nanoparticles and catalysis, John Wiley \& Sons, 2008.

8 C. J. Murphy, T. K. Sau, A. M. Gole, C. J. Orendorff, J. Gao, L. Gou, S. E. Hunyadi and T. Li, 2005.

9 A. Panáček, L. Kvitek, R. Prucek, M. Kolář, R. Večeřová, N. Pizúrová, V. K. Sharma, T. 'jana Nevěčná and R. Zbořil, J. Phys. Chem. B, 2006, 110, 16248-16253.

10 A. T. Bell, Science (80-. )., 2003, 299, 1688-1691.

11

J. E. Bauer, M. L. Occelli, P. M. Williams and P. C. McCaslin, Mar. Chem., 1993, 41, 75-89.

R. M. Rioux, H. Song, M. Grass, S. Habas, K. Niesz, J. D. Hoefelmeyer, P. Yang and G. A. Somorjai, Top. Catal., 2006, 39, 167-174.

Y. Li and G. A. Somorjai, Nano Lett., 2010, 10, 2289-2295.

J. H. Fendler and F. C. Meldrum, Adv. Mater., 1995, 7, 607-632.

A. R. Tao, S. Habas and P. Yang, small, 2008, 4, 310-325.

I. S. Helgadottir, P. P. Arquillière, P. Bréa, C. C. Santini, P.-H. Haumesser, K. Richter, A.-V. Mudring and M. Aouine, Microelectron. Eng., 2013, 107, 229-232.

H. Makhlouf, M. Weber, O. Messaoudi, S. Tingry, M. Moret, O. Briot, R. Chtoutou and M. Bechelany, Appl. Surf. Sci., , DOI:10.1016/j.apsusc.2017.07.130.

R. Viter, Z. Balevicius, A. Abou Chaaya, I. Baleviciute, S. Tumenas, L. Mikoliunaite, A. Ramanavicius, Z. Gertnere, A. Zalesska, V. Vataman, V. Smyntyna, D. Erts, P. Miele and M. Bechelany, J. Mater. Chem. C, 2015, 3, 6815-6821.

Z. Wang and S. M. Cohen, Chem. Soc. Rev., 2009, 38, 1315-1329.

Y. S. Li, H. Bux, A. Feldhoff, G. N. Li, W. S. Yang and J. Caro, Adv. Mater., 2010, 22, 3322-3326.

S. Kitagawa, Chem. Soc. Rev., 2014, 43, 5415-5418.

M. Bechelany, M. Drobek, C. Vallicari, A. A. Chaaya, A. Julbe and P. Miele, Nanoscale, 2015, 7, 57945802.

R. J. Kuppler, D. J. Timmons, Q.-R. Fang, J.-R. Li, T. A. Makal, M. D. Young, D. Yuan, D. Zhao, W. Zhuang and H.-C. Zhou, Coord. Chem. Rev., 2009, 253, 3042-3066.

J.-R. Li, R. J. Kuppler and H.-C. Zhou, Chem. Soc. Rev., 2009, 38, 1477-1504.

P. Falcaro, A. J. Hill, K. M. Nairn, J. Jasieniak, J. I. Mardel, T. J. Bastow, S. C. Mayo, M. Gimona, D. Gomez and H. J. Whitfield, Nat. Commun., 2011, 2, 237.

T. Tsuruoka, H. Kawasaki, H. Nawafune and K. Akamatsu, ACS Appl. Mater. Interfaces, 2011, 3, 37883791.

M. R. Lohe, K. Gedrich, T. Freudenberg, E. Kockrick, T. Dellmann and S. Kaskel, Chem. Commun., 2011, 47, 3075-3077.

S. Hermes, M. Schröter, R. Schmid, L. Khodeir, M. Muhler, A. Tissler, R. W. Fischer and R. A. Fischer, Angew. Chemie Int. Ed., 2005, 44, 6237-6241.

R. J. T. Houk, B. W. Jacobs, F. El Gabaly, N. N. Chang, A. A. Talin, D. D. Graham, S. D. House, I. M. Robertson and M. D. Allendorf, Nano Lett., 2009, 9, 3413-3418.

C. Zlotea, R. Campesi, F. Cuevas, E. Leroy, P. Dibandjo, C. Volkringer, T. Loiseau, G. Férey and M. Latroche, J. Am. Chem. Soc., 2010, 132, 2991-2997.

D. Esken, S. Turner, O. I. Lebedev, G. Van Tendeloo and R. A. Fischer, Chem. Mater., 2010, 22, 63936401.

M. Meilikhov, K. Yusenko, D. Esken, S. Turner, G. Van Tendeloo and R. A. Fischer, Eur. J. Inorg. Chem., 2010, 2010, 3701-3714.

M. S. El-Shall, V. Abdelsayed, S. K. Abd El Rahman, H. M. A. Hassan, H. M. El-Kaderi and T. E. Reich, J. Mater. Chem., 2009, 19, 7625-7631.

W.-I. Lee, S. Shrivastava, L.-T. Duy, B. Yeong Kim, Y.-M. Son and N.-E. Lee, Biosens. Bioelectron., 2017, 94, 643-650.

5 G. Lu, S. Li, Z. Guo, O. K. Farha, B. G. Hauser, X. Qi, Y. Wang, X. Wang, S. Han and X. Liu, Nat. Chem., 2012, 4, 310 . 
M. Ritala, K. Kukli, A. Rahtu, P. I. Räisänen, M. Leskelä, T. Sajavaara and J. Keinonen, Science (80-. )., 2000, 288, 319-321.

J. Hämäläinen, M. Ritala and M. Leskelä, Chem. Mater., 2013, 26, 786-801.

M. Baitimirova, R. Viter, J. Andzane, A. Van Der Lee, D. Voiry, I. Iatsunskyi, E. Coy, L. Mikoliunaite, S. Tumenas and K. Załęski, J. Phys. Chem. C, 2016, 120, 23716-23725.

V. Chawla, M. Ruoho, M. Weber, A. A. Chaaya, A. A. Taylor, C. Charmette, P. Miele, M. Bechelany, J. Michler and I. Utke, Nanomaterials, 2019, 9, 88.

B. Mårlid, M. Ottosson, U. Pettersson, K. Larsson and J. O. Carlsson, Thin Solid Films, 2002, 402, 167171.

H. Kim, J. Vac. Sci. Technol. B Microelectron. Nanom. Struct. Process. Meas. Phenom., 2003, 21, 22312261.

M. Weber, B. Koonkaew, S. Balme, I. Utke, F. Picaud, I. Iatsunskyi, E. Coy, P. Miele and M. Bechelany, ACS Appl. Mater. Interfaces, 2017, 9, 16669-16678.

L. Assaud, K. Pitzschel, M. Hanbücken and L. Santinacci, ECS J. Solid State Sci. Technol., 2014, 3, 253-258.

M. Weber, I. Iatsunskyi, E. Coy, P. Miele, D. Cornu and M. Bechelany, Adv. Mater. Interfaces, 2018, 5, $18-56$.

T. Aaltonen, M. Ritala, Y.-L. Tung, Y. Chi, K. Arstila, K. Meinander and M. Leskelä, J. Mater. Res., 2004, 19, 3353-3358.

M. J. Weber, A. J. M. Mackus, M. A. Verheijen, V. Longo, A. A. Bol and W. M. M. Kessels, J. Phys. Chem. C, 2014, 118, 8702 .

M. Leskelä and M. Ritala, Thin Solid Films, 2002, 409, 138-146.

S. M. George, Chem. Rev., 2010, 110, 111-131.

M. Leskelä and M. Ritala, Angew. Chemie - Int. Ed., 2003, 42, 5548-5554.

A. A. Malygin, V. E. Drozd, A. A. Malkov and V. M. Smirnov, Chem. Vap. Depos., 2015, 21, 216-240.

R. L. Puurunen, Chem. Vap. Depos., 2014, 20, 332-344.

E. Ahvenniemi, A. R. Akbashev, S. Ali, M. Bechelany, M. Berdova, S. Boyadjiev, D. C. Cameron, R. Chen, M. Chubarov and V. Cremers, J. Vac. Sci. Technol. A Vacuum, Surfaces, Film., 2017, 35, 10801.

R. W. Johnson, A. Hultqvist and S. F. Bent, Mater. Today, 2014, 17, 236-246.

I. J. Raaijmakers, ECS Trans., 2011, 41, 3-17.

M. B. O. Graniel, M. Weber, S. Balme, P. Miele, Biosens. Bioelectron., 2018, 122, 147-159.

M. Lepoitevin, T. Ma, M. Bechelany, J.-M. Janot and S. Balme, Adv. Colloid Interface Sci., 2017, 250, $195-213$.

M. Weber, A. Julbe, A. Ayral, P. Miele, M. Bechelany and B. M. Weber M., Julbe A., Ayral A., Miele P., Chem. Mater., 2018, 30, 7368-7390.

R. K. Ramachandran, C. Detavernier and J. Dendooven, in Nanotechnology in Catalysis, Wiley-VCH Verlag GmbH \& Co, 2017, pp. 335-358.

Z. Gao and Y. Qin, Acc. Chem. Res., 2017, 50, 2309-2316.

E.-L. Lakomaa, Appl. Surf. Sci., 1994, 75, 185-196.

M. Lindblad, L. P. Lindfors and T. Suntola, Catal. Letters, 1994, 27, 323-336.

M. Putkonen, in Atomic Layer Deposition of Nanostructured Materials, 2012, pp. 41-59.

A. J. M. Mackus, M. J. Weber, N. F. W. Thissen, D. Garcia-Alonso, R. H. J. Vervuurt, S. Assali, A. A. Bol, M. A. Verheijen and W. M. M. Kessels, Nanotechnology, , DOI:10.1088/0957-4484/27/3/034001.

J. A. Van Delft, D. Garcia-Alonso and W. M. M. Kessels, Semicond. Sci. Technol., 2012, 27, 074002.

M. J. Weber, J.-H. Kim, J.-H. Lee, J.-Y. Kim, I. Iatsunskyi, E. Coy, M. Drobek, A. Julbe, M. Bechelany and S. S. Kim, ACS Appl. Mater. Interfaces, 2018, 10, 34765-34773.

W. M. M. Kessels and M. Putkonen, MRS Bull., 2011, 36, 907-913.

G. N. Parsons, S. M. George and M. Knez, Mrs Bull., 2011, 36, 865-871.

H. Van Bui, F. Grillo and J. R. van Ommen, Chem. Commun., 2017, 53, 45-71.

H. Kim, H. B. R. Lee and W. J. Maeng, Thin Solid Films, 2009, 517, 2563-2580.

J. S. Ponraj, G. Attolini and M. Bosi, Crit. Rev. Solid State Mater. Sci., 2013, 38, 203-233.

C. T. Campbell, Surf. Sci. Rep., 1997, 27, 1-111.

A. J. M. Mackus, M. A. Verheijen, N. Leick, A. A. Bol and W. M. M. Kessels, Chem. Mater., 2013, 25, 1905-1911.

3 N. Leick, J. W. W. Weber, A. J. M. J. M. Mackus, M. J. J. Weber, M. C. M. C. M. Van de Sanden and W. M. M. M. M. Kessels, J. Phys. D. Appl. Phys., 2016, 49, 115504.

F. Grillo, J. A. Moulijn, M. T. Kreutzer and J. R. van Ommen, Catal. Today, 2018, 316, 51-61.

F. Grillo, H. Van Bui, J. A. Moulijn, M. T. Kreutzer and J. R. van Ommen, J. Phys. Chem. Lett., 2017, 8, 975-983. 
B. S. Lim, A. Rahtu and R. G. Gordon, Nat. Mater., 2003, 2, 749-754.

J. W. Elam, A. V. V Zinovev, M. J. Pellin, D. J. Comstock and M. C. Hersam, ECS Trans., 2007, 3, 271-278.

S. S. Masango, L. Peng, L. D. Marks, R. P. Van Duyne and P. C. Stair, J. Phys. Chem. C, , DOI:10.1021/jp504067c.

M. B. E. Griffiths, P. J. Pallister, D. J. Mandia and S. T. Barry, Chem. Mater., 2015, 28, 44-46.

H. Feng, J. W. Elam, J. A. Libera, W. Setthapun and P. C. Stair, Chem. Mater., 2010, 22, 3133-3142.

J. Lu and P. C. Stair, Angew. Chemie Int. Ed., 2010, 49, 2547-2551.

L. Assaud, N. Brazeau, M. K. S. Barr, M. Hanbücken, S. Ntais, E. A. Baranova and L. Santinacci, ACS Appl. Mater. Interfaces, 2015, 7, 24533-24542.

G. A. Ten Eyck, S. Pimanpang, H. Bakhru, T. Lu and G. Wang, Chem. Vap. Depos., 2006, 12, 290-294.

M. K. S. Barr, L. Assaud, N. Brazeau, M. Hanbücken, S. Ntais, L. Santinacci and E. A. Baranova, J. Phys. Chem. C, 2017, 121, 17727-17736.

L. Assaud, E. Monyoncho, K. Pitzschel, A. Allagui, M. Petit, M. Hanbücken, E. A. Baranova and L. Santinacci, Beilstein J. Nanotechnol., 2014, 5, 162.

M. Weber, C. Lamboux, B. Navarra, P. Miele, S. Zanna, M. Dufond, L. Santinacci and M. Bechelany, Nanomaterials, 2018, 8, 849.

T. Gong, L. Qin, W. Zhang, H. Wan, J. Lu and H. Feng, J. Phys. Chem. C, 2015, 119, 11544-11556.

E. Rikkinen, A. Santasalo-Aarnio, S. Airaksinen, M. Borghei, V. Viitanen, J. Sainio, E. I. Kauppinen, T. Kallio and A. O. I. Krause, J. Phys. Chem. C, 2011, 115, 23067-23073.

X. Liang, L. B. Lyon, Y.-B. Jiang and A. W. Weimer, J. Nanoparticle Res., 2012, 14, 943.

M. Weber, P. Collot, H. El Gaddari, S. Tingry, M. Bechelany and Y. Holade, ChemElectroChem, 2018, 5, 743-747.

C. Liu, C. Wang, C. Kei, Y. Hsueh and T. Perng, Small, 2009, 5, 1535-1538.

W. Setthapun, W. D. Williams, S. M. Kim, H. Feng, J. W. Elam, F. A. Rabuffetti, K. R. Poeppelmeier, P. C. Stair, E. A. Stach and F. H. Ribeiro, J. Phys. Chem. C, 2010, 114, 9758-9771.

S. T. Christensen, H. Feng, J. L. Libera, N. Guo, J. T. Miller, P. C. Stair and J. W. Elam, Nano Lett., 2010, 10, 3047-3051.

A. J. M. Mackus, M. J. M. Merkx and W. M. M. Kessels, Chem. Mater.

M. J. J. Weber, M. A. A. Verheijen, A. A. A. Bol and W. M. M. M. M. Kessels, Nanotechnology, 2015, 26, 094002 .

M. J. Weber, A. J. M. MacKus, M. A. Verheijen, C. Van Der Marel and W. M. M. Kessels, Chem. Mater., , DOI:10.1021/cm301206e.

J. Lu, K.-B. Low, Y. Lei, J. A. Libera, A. Nicholls, P. C. Stair and J. W. Elam, Nat. Commun., 2014, 5, 3264.

M. Weber, J.-H. Kim, J.-H. Lee, J.-Y. Kim, I. Iatsunskyi, E. Coy, M. Drobek, A. Julbe, M. Bechelany and S. S. Kim, ACS Appl. Mater. Interfaces, 2018, 10, 34765-34773.

R. C. Klet, T. C. Wang, L. E. Fernandez, D. G. Truhlar, J. T. Hupp and O. K. Farha, Chem. Mater., 2016, 28, 1213-1219.

K. Leus, J. Dendooven, N. Tahir, R. K. Ramachandran, M. Meledina, S. Turner, G. Van Tendeloo, J. L. Goeman, J. Van der Eycken and C. Detavernier, Nanomaterials, 2016, 6, 45-56.

M. Meledina, S. Turner, M. Filippousi, K. Leus, I. Lobato, R. K. Ramachandran, J. Dendooven, C. Detavernier, P. Van Der Voort and G. Van Tendeloo, Part. Part. Syst. Charact., 2016, 33, 382-387. 